\title{
Synthesis of Verubecestat
}<smiles>O=[13C](O)c1cc(Br)ccc1F</smiles>

B (2.0 equiv)<smiles>CC1=NS(=O)(=O)OC1</smiles>

A (1.0 equiv)

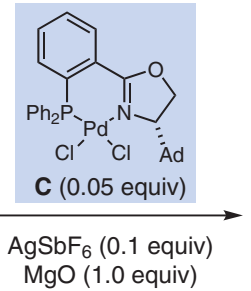

DCB $70^{\circ} \mathrm{C}, 10 \mathrm{~h}$

$90 \%(1.0 \mathrm{mmol}$ scale $)$

$\mathrm{DCB}=1,2$ dichlorobenzene $\mathrm{Ad}=$ adamantyl<smiles>O=S1(=O)NC(c2cc(Br)ccc2F)CO1</smiles>

D
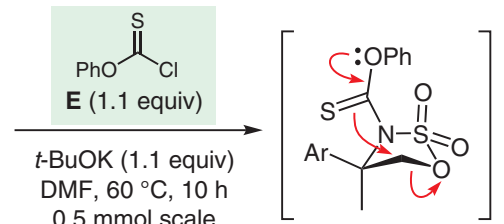

F

Synthesis of Natural

Products and

Potential Drugs

Key words

verubecestat

$\beta$-secretase inhibtor

palladium-catalyzed arylation

enantioselective addition

ketimines

iminosulfates

sulfamidates

Synfacth of the wown<smiles></smiles>

$\mathrm{H}$

Significance: Verubecestat (MK-8931) is a $\beta$-secretase inhibitor that is of interest for the treatment of Alzheimer's disease. The key step in the $\mu \mathrm{mol}$-scale synthesis depicted is the construction of the aza-quaternary center in fragment $\mathbf{D}$ through a palladium-catalyzed, enantioselective addition of arylboronic acid $\mathbf{B}$ to cyclic iminosulfate A. The desired cyclic sulfamidate $\mathbf{D}$ was obtained in 90\% yield and 99\% ee.
Comment: The scope of the palladium-catalyzed enantioselective arylation reaction was explored using seven cyclic iminosulfates and eleven arylboronic acids. The reaction tolerates electron-rich, electron-poor, and ortho-substituted arylboronic acids and provides cyclic sulfamidates in high yields with excellent enantioselectivities. This palladium catalyst system significantly expands the scope for the asymmetric arylation of ketimines.

SYNFACTS Contributors: Philip Kocienski

Synfacts 2018, 14(06), 0555 Published online: 17.05.2018 DOI: 10.1055/s-0037-1609518; Reg-No.: K02018SF 